Eechnical Note

$n_{0.20}$

Boulder Laboratories

\title{
A PRELIMINARY ANALYSIS OF AMPLITUDE SCINTILLATIONS \\ OF RADIO STARS OBSERVED AT BOULDER , COLORADO
}

BY ROBERT S. LAWRENCE AND JAMES L. JESPERSEN 



\title{
NATIONAL BUREAU OF STANDARDS Eechnical Note
}

\author{
20 \\ July, 1959 \\ A PRELIMINARY ANALYSIS OF AMPLITUDE SCINTIUJATIONS \\ OF RADIO STARS OBSERVED AT BOULDER, COLORADO \\ by \\ Robert S. Lawrence \\ and \\ James L. Jespersen \\ NBS Technical Notes are designed to supplement the Bu- \\ reau's regular publications program. They provide a \\ means for making available scientific data that are of \\ transient or limited interest. Technical Notes may be \\ listed or referred to in the open literature. They are for \\ sale by the Office of Technical Services, U. S. Depart- \\ ment of Commerce, Washington 25, D. C.
}

\section{DISTRIBUTED BY \\ UNITED STATES DEPARTMENT OF COMMERCE OFFICE OF TECHNICAL SERVICES}

WASHINGTON 25, D. C.

Price $\$ 1.00$ 

A PRELIMINARY ANALYSIS OF AMPLITUDE SCINTILIATIONS OF RADIO STARS OBSERVED AT BOULDER, COLORADO

$$
\text { by }
$$

\author{
Robert S. Lawrence \\ and
}

James L. Jespersen

This work has been sponsored by the USAF, under D.0. AF 04(647) -134 

TABLE OF CONTENTS

Introduction . . . . . . . . . . . . . . . . . I

1. Description of the experiment .......... I

2. Data Analysis ............... 2

Ionograms . . . . . . . . . . . . . . 2

Scintillation Indices........... 2

Correlation of IBM cards. ..........4

3. Results ............... 5

Distribution of amplitude and flux values .... . 5

Comparison between the two frequencles...... 5

Correlation with Ellsworth lonograms. . . . . . 6

4. Discussion of results . . . . . . . . 7

Amplitude and flux distributions. . . . . . . 7

Comparison between the two frequencles...... 9

Correlation with spread F . . . . . . . . 9

Correlation with sporadic E . . . . . . . I0

References . . . . . . . . . . . . . . .12

Appendix: The relation between amplitude and power indices for a Rice distribution. . . . . . . . 14 



\section{ABSTRACT}

Variations in the apparent flux from the radio source Cygnus-A are recorded at 53 and $108 \mathrm{mc} / \mathrm{s}$ using a two-element phase-sweeping interferometer located at Boulder. An 1onospheric sounder operating at Ellsworth, Nebraska, provides simultaneous vertical-incidence measurements of the ionosphere along the path. Amplitude scintillations observed at Boulder over a six-month period are compared with the lonograms taken at Ellsworth. Positive correlation is found between amplitude scintillations and spread $F$, while a small negative correlation is found with sporadic $\mathrm{E}$. The present result appears to be significant but a full year's data are being accumulated to disclose seasonal or diurnal effects. Detailed analysis of the scintillations indicates that the probability distribution of the amplitude can be represented by the Rice probability distribution function. The scintillation rate for $108 \mathrm{mc} / \mathrm{s}$ seems to be more rapid than for $53 \mathrm{mc} / \mathrm{s}$. 

OF RADIO STARS OBSERVED AT BOULDER, COLORADO

by

Robert S. Lawrence

and

James L. Jespersen

\section{Introduction}

It has been recognized since 1950 that the apparent fluctuations in intensity of discrete radio sources arise in the ionosphere. The F region is generally believed to play an important role in the production of these scintillations, but our knowledge of the effect of the $\mathrm{E}$ region is confused by incomplete and apparently conflicting evidence. One of the purposes of an experiment now in progress at the Boulder Laboratories is to improve our understanding of the ionospheric conditions and levels responsible for the scintillations. A description of the planning and instrumentation for the experiment, along with a brief summary of the pertinent literature has already appeared ${ }^{I}$.

The present report deals with amplitude scintillations observed at Boulder and with the comparison between them and ionograms taken at Ellsworth, Nebraska. It must be considered preliminary, in that it describes data for only six months, February through July, 1958, and the relationship between sidereal and solar time dictates that a full year's data are required to distinguish between diurnal and elevation-angle effects.

\section{Description of the Experiment}

The apparent flux from the radio source Cygnus-A is recorded at Boulder at frequencies of 53 and $108 \mathrm{mc} / \mathrm{s}$, using a two-element, phase-sweeping interferometer with an east-west spacing of 475 meters. ${ }^{1}$ At the time when Cygnus-A is about $15^{\circ}$ above the north-east horizon, the line of sight intersects the $\mathrm{E}$ region over Ellsworth, Nebraska. An ionospheric sounder operates at Ellsworth at five-minute intervals to provide simultaneous information concerning the ionsophere along the path. As the source rises above $15^{\circ}$, the intersection point moves from Ellsworth toward Boulder. Figure ( 1 ) is a map of the BoulderEllsworth region showing the plan view of the intersection point for 



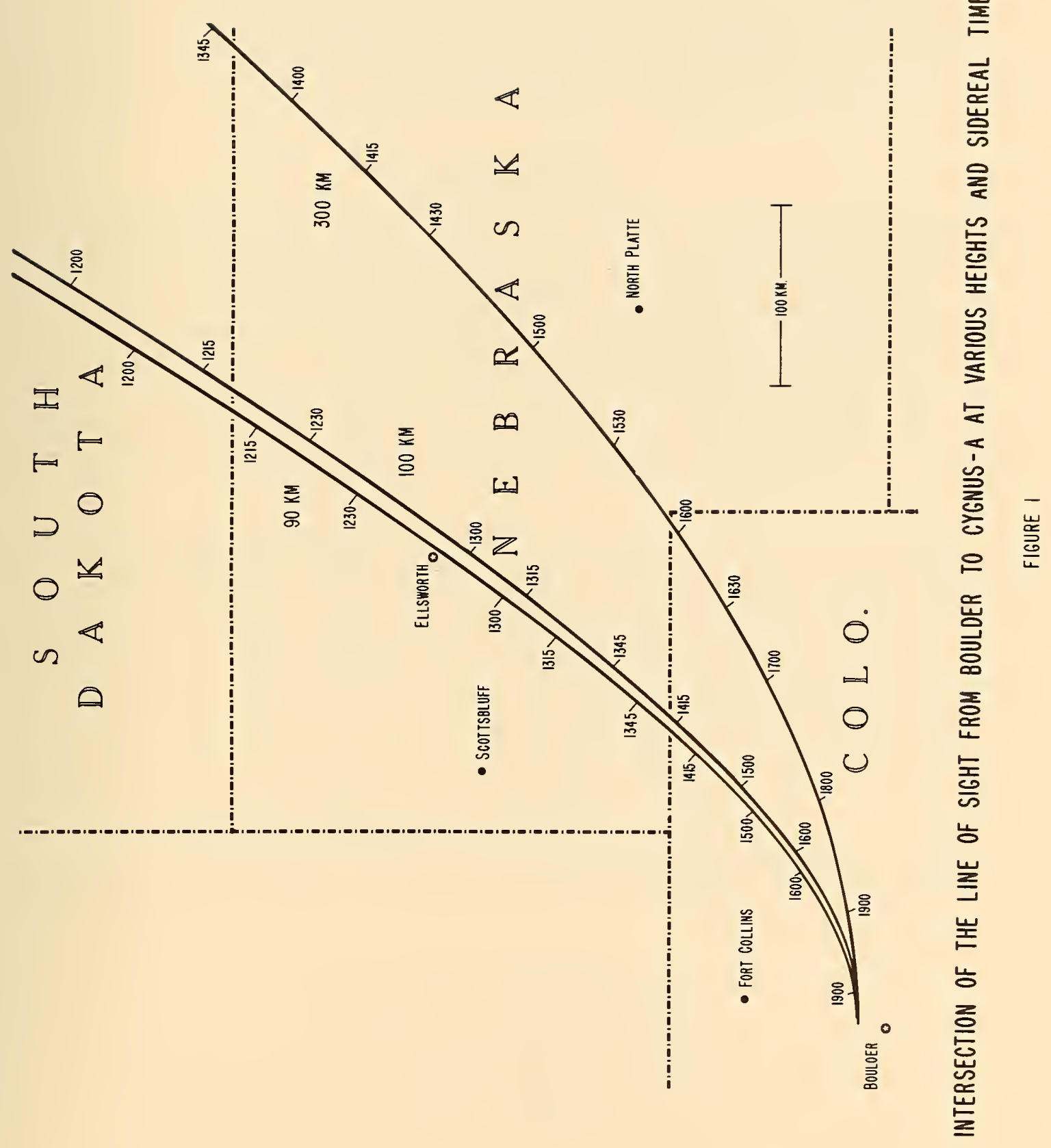



various ionospheric heights. The numbers along the loci indicate the local sidereal time (LST) at Boulder.

The 90 and 100 kilometer intersections both pass nearly overhead at Ellsworth, but at different times. The 300 kilometer intersection point comes to within less than $100 \mathrm{~km}$ of Ellsworth about two and one-half hours later. Notice that for each ionospheric height there is a time when any agreement between the scintillations at Boulder and the vertical measurements at Ellsworth should be most pronounced. Conversely, the time of best agreement is indicative of a unique height.

\section{Data Analysis}

Ionograms. Ellsworth ionograms are made at five-minute intervals each day from 1230 unt1l 1330 LST, and are made at half-hour intervals for the next three hours. Each lonogram is scaled for critical frequencies, minimum virtual heights, and for the occurrence and type of special features, especially spread-F and sporadic-E traces. Absence or presence of spread F (or sporadic E) is indicated by an index which has only two values, 1 and 2. For each ionogram, the scaled information is punched on an IBM card, and to this card is added a set of scintillation indices obtained from the scintillation records for the same five-minute interval.

Scintillation indices. Figure $2 a$ is a twelve-minute section of a typical scintillation record. The trace shows the $10 \mathrm{cycle} / \mathrm{minute}$ sine wave generated by the phase-sweeping interferometer as the lobes pass across Cygnus-A. The height of the envelope of this trace is proportional to the received flux from the discrete source. The fluctuation in this envelope is the amplitude scintillation caused by the ionosphere. Figure $2 \mathrm{~b}$ shows a record in which the scintillations are much deeper and more rapid. Many of these records are available not only as pen recordings, but in digital form on punched paper tape which can be fed directly to an electronic computer.

The records are classified by eye as to depth and rate of the amplitude fluctuations. The depth index consists of a scale of five, described as:

1. no scintillations,

2. shallow scintillations,

3. medium scintillations,

4. deep scintillations,

5. scintillations so deep that the signal disappears. 


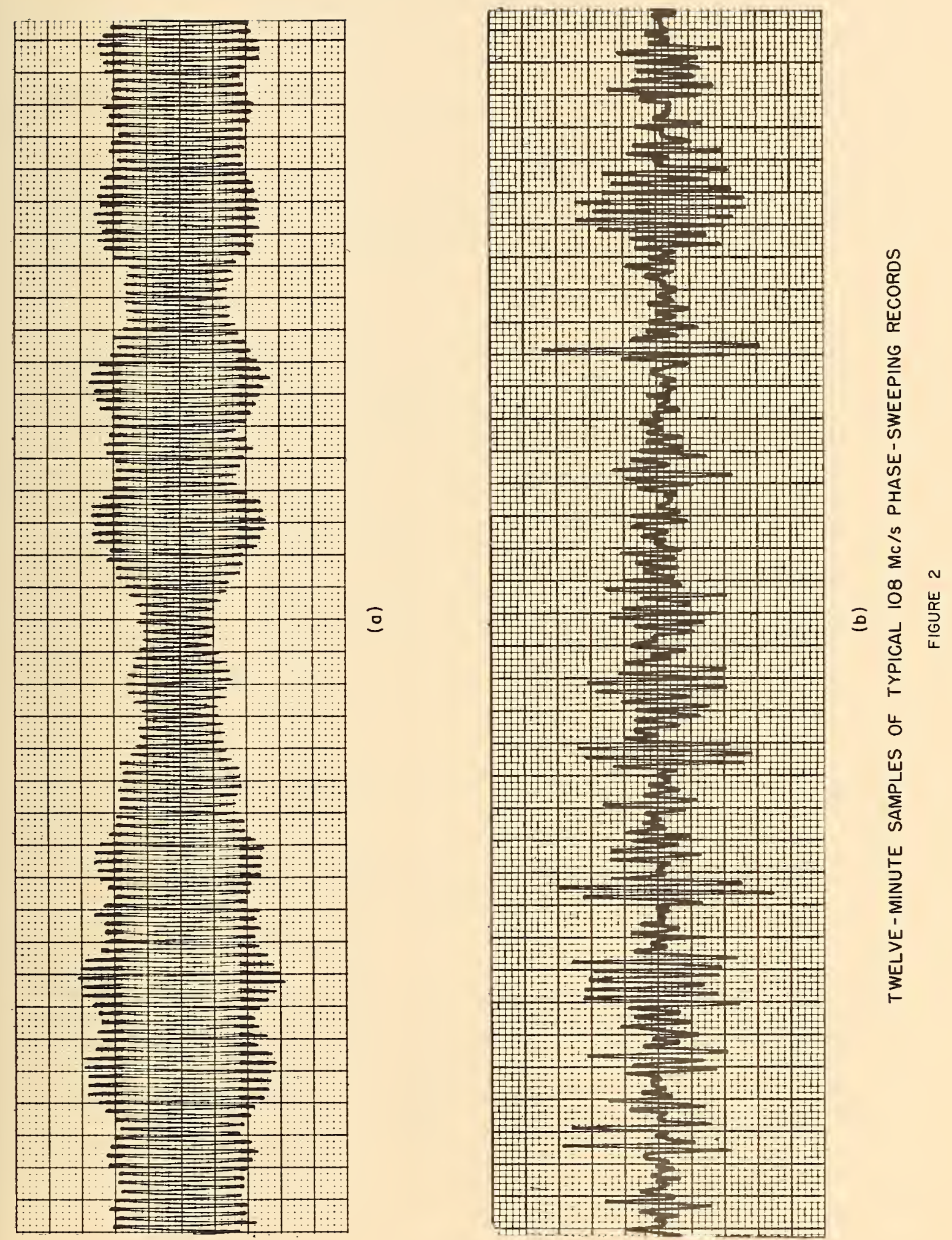
Several records bearing each index have been analyzed with the computer to determine both the power index,

$$
\frac{\Delta P}{P} \equiv\left|\frac{P-\bar{P}}{\bar{P}}\right| \text {, }
$$

and the amplitude index,

$$
\left(\frac{\Delta A}{A}\right)^{2} \equiv \overline{\left(\frac{A-\bar{A}}{\bar{A}}\right)^{2}}
$$

where $P$ is the power received from the radio star, $A=\sqrt{P}$ is the amplitude of the radio signal, and a bar denotes an average over the record. The results are summarized in the table below.

\begin{tabular}{|c||ccc||ccc|}
\hline \multirow{2}{*}{$\begin{array}{c}\text { depth } \\
\text { index }\end{array}$} & \multicolumn{3}{|c|}{$\Delta \mathrm{P} / \mathrm{P}$} & \multicolumn{3}{|c|}{$(\triangle \mathrm{A} / \mathrm{A})^{2}$} \\
\cline { 2 - 6 } & min. & mqx. & avg. & min. & $\max$. & avg. \\
\hline 1 & .04 & .13 & .09 & .0008 & .0071 & .0025 \\
2 & .06 & .14 & .10 & .0016 & .0083 & .0045 \\
3 & .14 & .35 & .23 & .0092 & .0448 & .0238 \\
4 & .30 & .39 & .35 & .0377 & .0575 & .0512 \\
5 & .44 & .75 & .57 & .0838 & .3237 & .1689 \\
\hline
\end{tabular}

The rate index consists of a scale of four, described in terms of the apparent "period" of the scintillations, as follows:

1. no scintillations,

2. period greater than 2 minutes,

3. period 1 to 2 minutes,

4. period less than 1 minute.

This classification is more subjective than the depth index because the scintillations have no unique period. After the rate index had been assigned by eye, several records from each group were smoothed with an 18-second running average and then measured to find the average interval between crossings of $\bar{P}$. The apparent "period", $t$, is defined as twice that interval. The table below sumarizes the results of this analysis. 
. 


\begin{tabular}{|c||c|c|c|}
\hline \multirow{2}{*}{ rate } & \multicolumn{3}{|c|}{$\mathrm{t}$} \\
\cline { 2 - 4 } index & $\min$. & $\max$. & avg. \\
\hline \multirow{2}{*}{1} & \multicolumn{3}{|c|}{ no scintillations } \\
2 & 1.8 & 4.2 & 2.7 \\
3 & 0.8 & 1.6 & 1.1 \\
4 & 0.7 & 1.4 & 0.9 \\
\hline
\end{tabular}

Correlation of IBM cards. The IBM cards containing the scintillation indices and the readings from the ionograms are used to determine the correlation between any two of the above-mentioned variables $\mathrm{x}$ and y. The correlation coefficlent is defined in the usual way as

$$
r=\frac{\overline{x y}-\bar{x} \bar{y}}{\sigma_{x} \sigma_{y}}
$$

where the variance, $\quad \sigma_{x}^{2}=\overline{x^{2}}=\overline{x^{2}}$.

If all the data are independent and normally distributed the standard deviation of the correlation coefficient is

$$
\sigma_{r}=\frac{1-r^{2}}{\sqrt{N}}
$$

where $N$ is the number of samples. If the data are not independent, but the serial correlation is significant over a span of $n$ samples, $\mathbb{N}$ in (2) should be replaced by $\mathrm{N} / \mathrm{n}$ so as to include only independent samples. A brief inspection of the data indicates that a typical value of $n$ for the scintillation records is 6 .

With the depth and rate indices as they have been defined the distribution of scintillation data is by no means normal, but is strongly skewed toward the high indices. Figure 3 shows the histograms of scintillation indices on all the IBM cards used in the present comparison with the ionograms. (These histograms are not representative of all scintillations, as the data considered here are strongly blased toward elevation angles of $15^{\circ}$.) In order to assess the error introduced by using the simple relationship (2), a more sophisticated analysis ${ }^{2}$, involving higher moments of the actual distribution, was made of a typical correlation coefficient taken from our data. The difference in $\sigma_{r}$ amounted to less than .001 , and equation (2) has been used for all subsequent calculations of $\sigma_{r}$. 


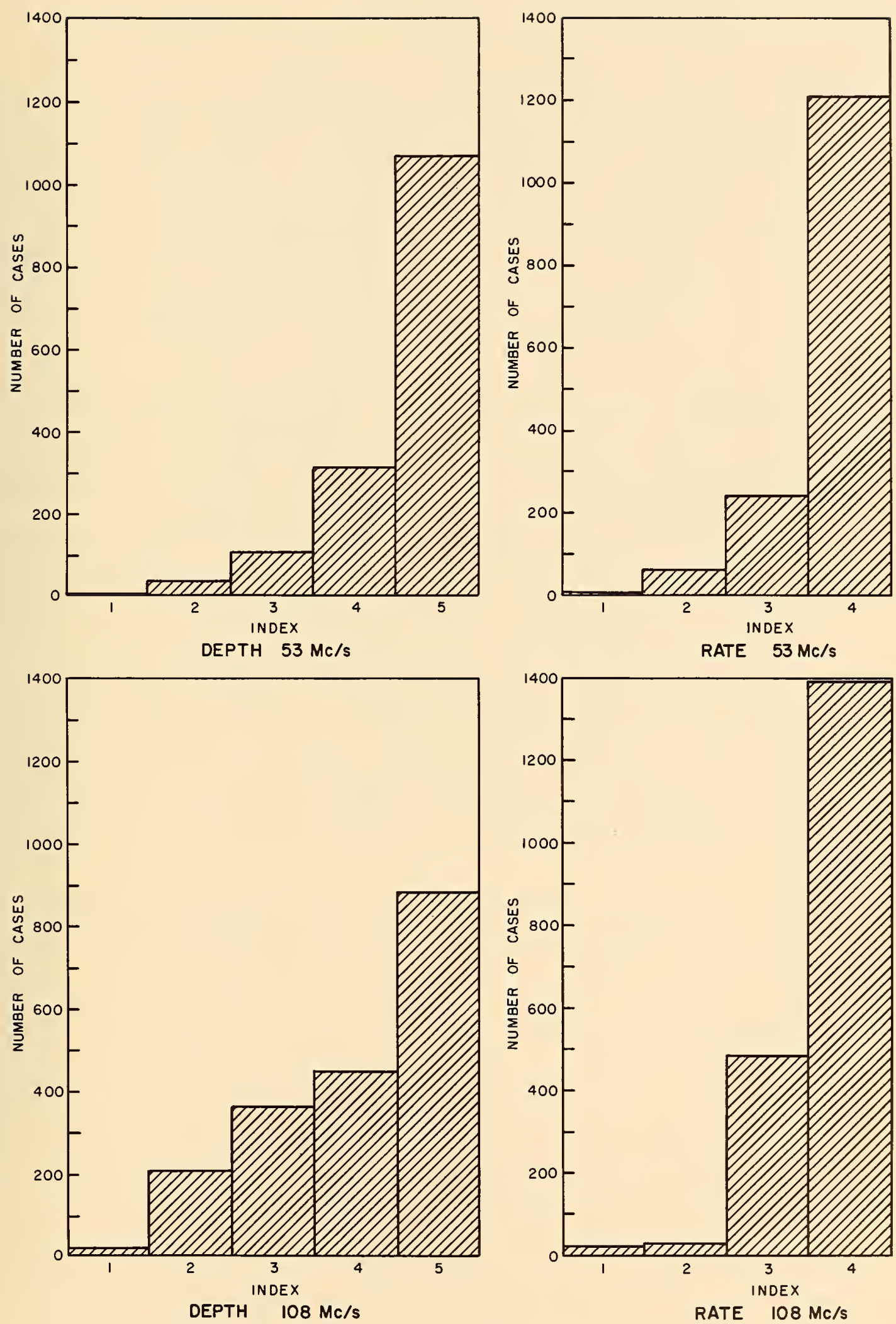

THE DISTRIBUTION OF SCINTILLATION INDICES USED IN THE ANALYSIS OF DATA FEBRUARY THROUGH JULY, 1958 

Distribution of amplitudes and flux values. Amplitude scintillations have been measured and discussed by various authors in at least two very different ways. Observations made in Cambridge, England have been reported ${ }^{3}$ in terms of a fluctuation index derived by dividing the root-mean-square fluctuation in amplitude by the mean amplitude recelved from the source, i.e. in terms of the quantity

$$
\frac{\sqrt{(\bar{A}-\bar{A})^{2}}}{\bar{A}}=\sqrt{\left(\frac{A-\bar{A}}{\bar{A}}\right)^{2}}=\sqrt{\left(\frac{\Delta A}{A}\right)^{2}} \text {, }
$$

the square root of our $\left(\frac{\Delta A}{A}\right)^{2}$. The observations from College, Alaska are reported ${ }^{4}$ in terms of $\frac{\Delta P}{P}$. Results from Manchester, England were reported ${ }^{5,6}$ in terms of a fluctuation index which was approximately $3 \frac{1}{2}$ times larger than $\frac{\Delta P}{P}$. Booker, in his recent discussion ${ }^{7}$ of scintillations, uses the quantity $\left(\frac{\Delta A}{A}\right)^{2}$ and mentions the difficulties involved in converting from one system of measurement to another.

The relationship between $\frac{\triangle P}{P}$ and $\left(\frac{\Delta A}{A}\right)^{2}$ depends upon the distribution law obeyed by the amplitude, A, of the radio wave. Thirty-one records, selected at random and analyzed with the computer, gave the values of $\frac{\triangle P}{P}$ and $\left(\frac{\triangle A}{A}\right)^{2}$ shown by the dots in figure 4. The solid curve, a theoretical one, is described in section 4.

Comparison between the two frequencies. Quantitative comparison between the scintillations observed at 53 and $108 \mathrm{mc} / \mathrm{s}$ can best be made not with the subjective depth and rate indices used for the statistical analysis, but with detailed analysis of pairs of simultaneous records made at the two frequencies. Several such pairs of records have been analyzed with the computer to get both $t$ and $\left(\frac{\Delta A}{A}\right)^{2}$. The comparison of fading "periods" is displayed in figure $5 \mathrm{a}$ where $1 t$ can be seen that the $53 \mathrm{mc} / \mathrm{s}$ scintillations seem to be consistently slower than those at $108 \mathrm{mc} / \mathrm{s}$. The amplitude indices, $\left(\frac{\Delta A}{A}\right)^{2}$, are related as shown in figure $5 \mathrm{~b}$. The two lines show the locations to be expected for the points if the amplitude index varied as $\lambda^{2}$ or $\lambda^{4}$. 



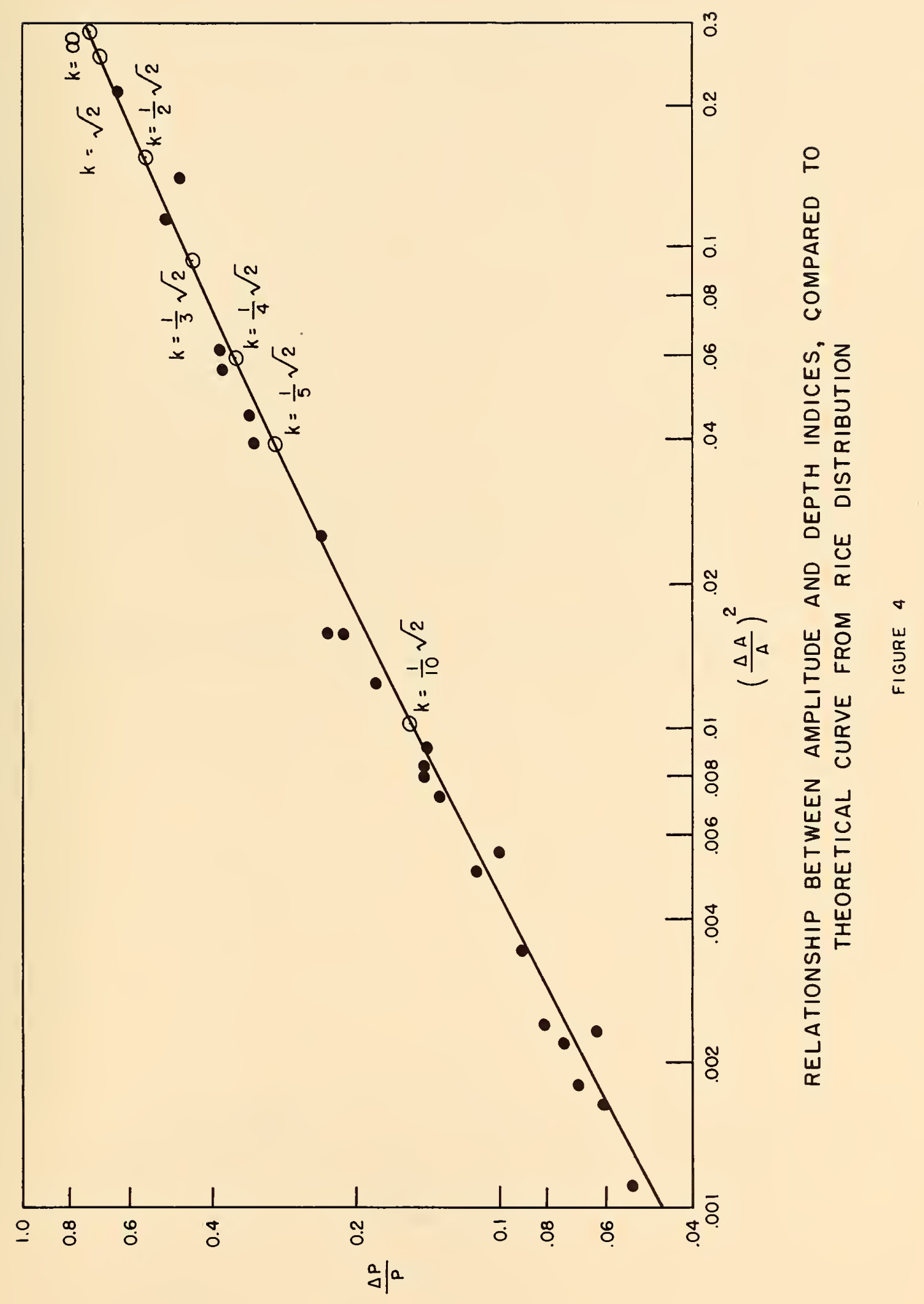





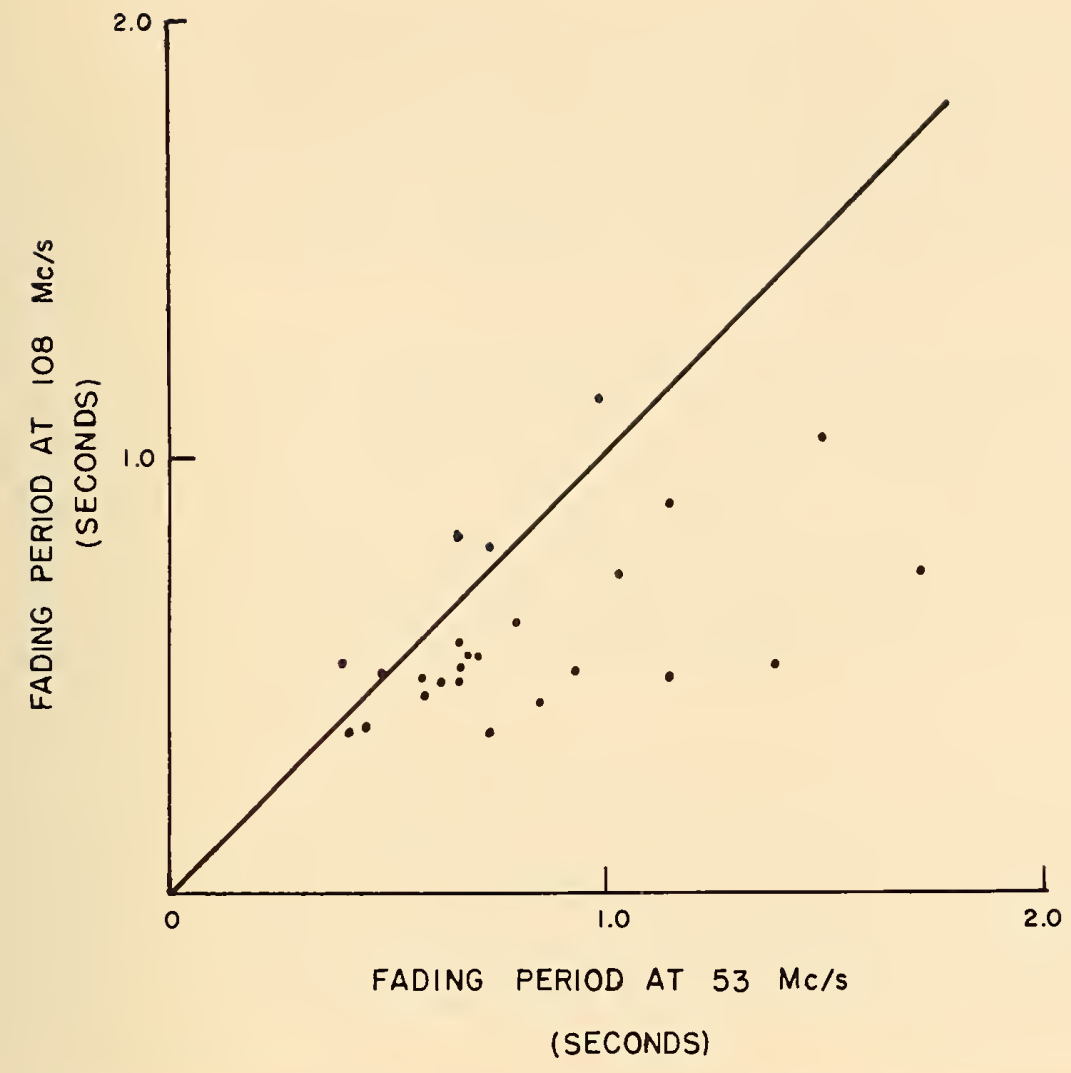

COMPARISON OF FADING PERIODS AT TWO FREQUENCIES

FIGURE 50

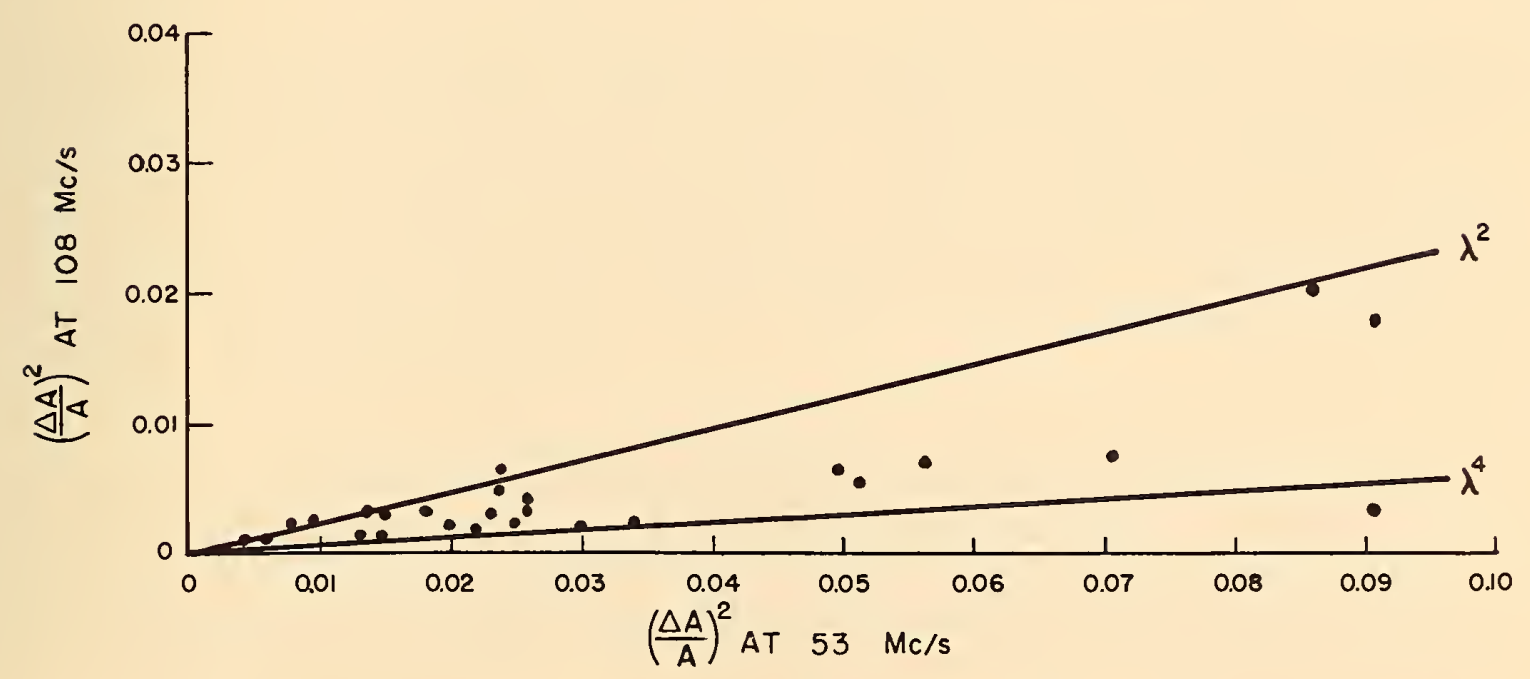

COMPARISON OF AMPLITUDE INDICES AT TWO FREQUENCIES 

Correlation with Ellsworth ionograms. We have seen from figure I that the degree to which agreement can be expected between the scintillation indices and any particular feature of the Ellsworth ionograms is a function of sidereal time and of the height of the effective ionospheric region. Accordingly, for correlation studies the data were first separated into four groups depending upon sidereal time.

The upper diagram in figure 6 shows the four correlation coefficients for the depth index of $108 \mathrm{mc} / \mathrm{s}$ scintillations versus the occurrence of spread $F$ on the ionograms. The vertical bar through each point has length $2 \sigma_{r}$. The abscissa on this diagram is labeled both with local sidereal time and with the corresponding effective height for which best agreement would be expected at that time. The correlation coefficients, though small, seem to be significant and they increase for high effective heights as would be expected for an F-region phenomenon.

The corresponding graphs for the rate index at $108 \mathrm{mc} / \mathrm{s}$, and for the depth and rate indices at $53 \mathrm{mc} / \mathrm{s}$, are not shown, but they all exhibit similar behavior when correlated with spread $F$. When the data are divided into two three-month sets, each independently shows the same effect, but naturally the standard deviations are slightly larger. The significance of these correlations is discussed in section 4.

The lower diagram in figure 6 shows the result of correlating the depth index at $108 \mathrm{mc} / \mathrm{s}$ with sporadic $\mathrm{E}$. Here the correlation is negative and, as would be expected for an E-region phenomenon, its absolute value is a maximum at low effective heights. The $53 \mathrm{mc} / \mathrm{s}$ depth index gives the same result. The rate indices for both $108 \mathrm{mc} / \mathrm{s}$ and $53 \mathrm{mc} / \mathrm{s}$ scintillations appear to be uncorrelated with sporadic $\mathrm{E}$.

In order to check more closely the negative correlation with sporadic $E$, the data were separated according to the type of sporadic $E$. Of the standard IGY types in accordance with which the ionograms were scaled, one (Type " $l$ ") is described as "a flat Es trace below the normal E layer minimum virtual height." This type, which we refer to as "low-level" sporadic E was separated from all other types (referred to as "high-level"), and the curves shown in figure 7 result. The negative correlation appears in both types, and the effective heights vary in the proper direction.

This apparent statistical connection between scintillations and sporadic $E$ stimulated a search for specific cases in which the scintillation records change character at the time when sporadic $\mathbb{E}$ appears or disappears at Ellsworth. Spectacular results cannot be expected from such a search for several reasons, and the statistical significance is difficult to assess. The sporadic-E appearance must 


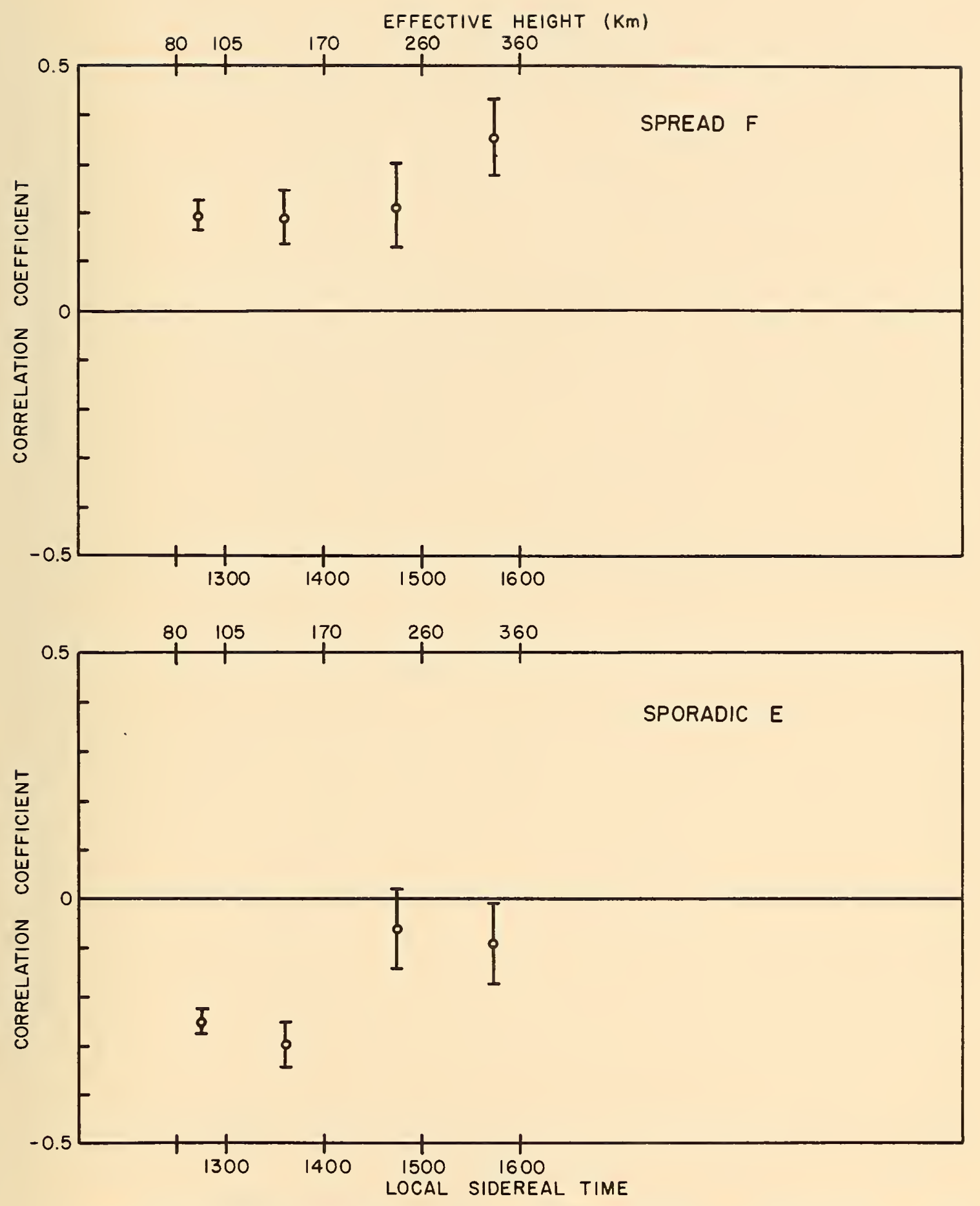

CORRELATION OF $108 \mathrm{Mc} / \mathrm{s}$ SCINTILLATION DEPTH WITH SPREAD F AND SPORADICE.

FIGURE 6 


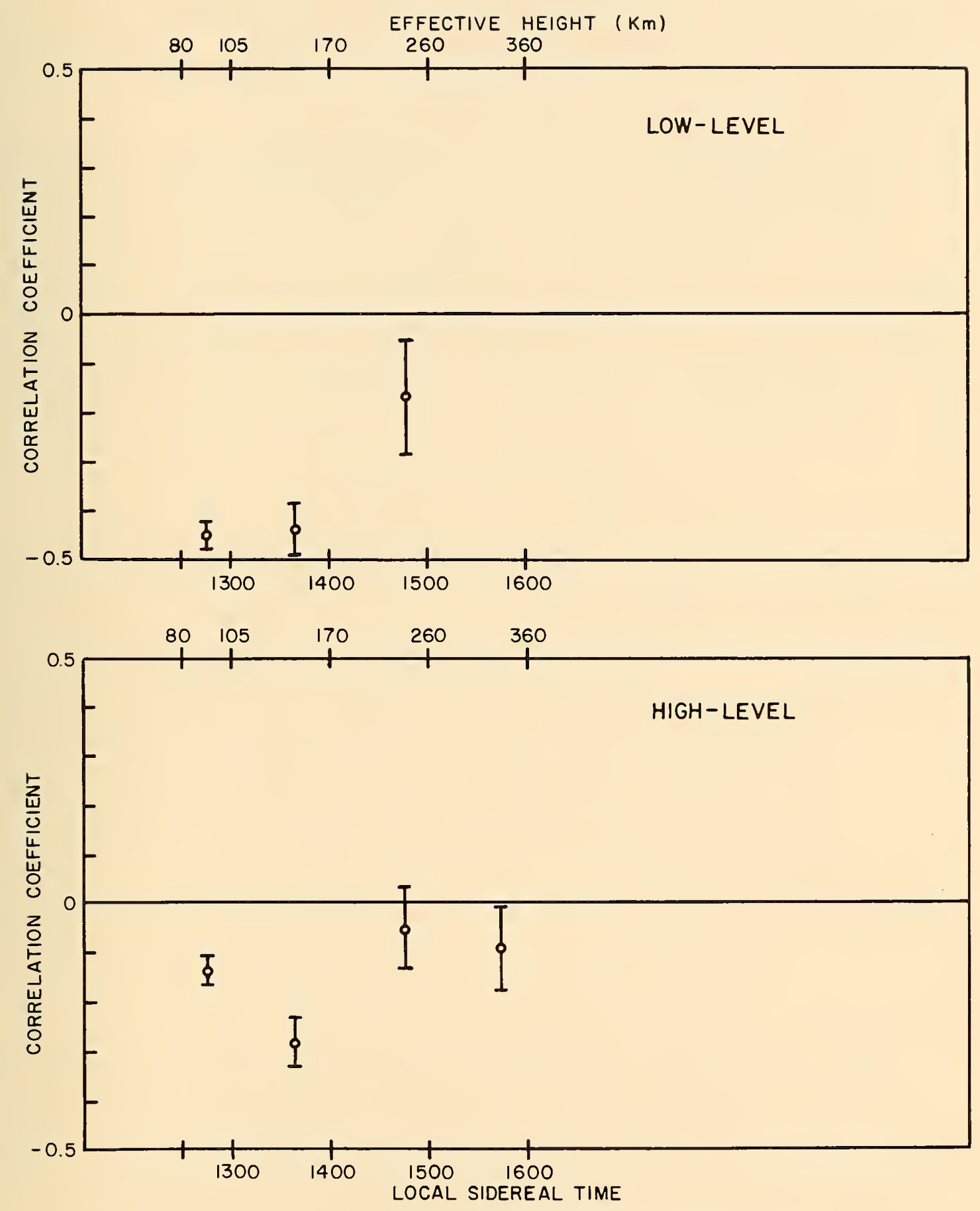

CORRELATION OF $108 \mathrm{MC} / \mathrm{s}$ SCINTILLATION DEPTH WITH HIGH-LEVEL AND LOW-LEVEL SPORADIC E. FIGURE 7 

occur within about an hour of the proper sidereal time since it is known 8 that vertical-incidence measurements of sporadic $E$ only $100 \mathrm{~km}$ apart often show only slight correlation. The elevation angle of the radio star is changing at this time at a rate of about $10^{\circ}$ per hour, and this causes a continuously changing appearance of the scintillation record even in the absence of ionospheric changes.

From the six months of available data there are two cases where the scintillation record seems to change in synchronism with the sporadic $E$ on the ionograms, and two or three others where the effect is more questionable or absent. Figure 8 shows the scintillation record from 1302 to 1401 LST on April 17, 1958. Sporadic E was present on ionograms taken at 1317, 1322, 1327, and 1332. It was absent at 1312 and earlier, and also at 1337 and later. The character of the scintillation trace appears to be different during a period roughly coincident with the apparition of sporadic E. The principal effect seems to be a reduction of the amplitude of the scintillations, although there is some evidence of a decrease in average flux.

\section{Discussion of Results}

Amplitude and flux distributions. Figure 4 shows that the observed values of amplitude index, $\left(\frac{\triangle A}{A}\right)^{2}$, and power index, $\frac{\triangle P}{P}$, lie close to a smooth curve. Since the relationship between these two indices depends upon the distribution function of the amplitude of the radio wave, this result gives us some information about the distribution functions themselves. Any particular probability density function would produce a single value of $\left(\frac{\Delta A}{A}\right)^{2}$ and a corresponding single value of $\frac{\triangle P}{P}$. The fact that the points on figure 4 lie near a single smooth curve implies that the family of probability density functions from which our scintillation samples have been taken can be described by a single parameter, the position along the line depending upon the value of that parameter.

The solid line in the figure shows the theoretical relationship which would occur if the observed signal were composed of a steady (undiffracted) component and a random component consisting of a number (three, or more) of independent, randomly-phased, diffracted waves. The probability density function from which this curve has been derived was first described by Rice 9 and has been discussed in terms of its application to ionospheric problems by Ratcliffel0. This probability density function, which we shall call the Rice distribution, is really a family of distribution functions parametric in the quantity 

CYGNUS - A

APRIL 17, 1958

$53 \mathrm{MC} / \mathrm{s}$

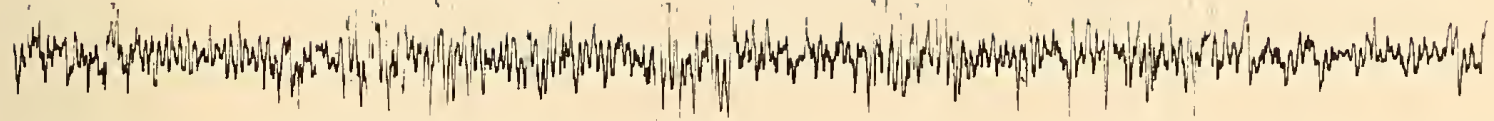

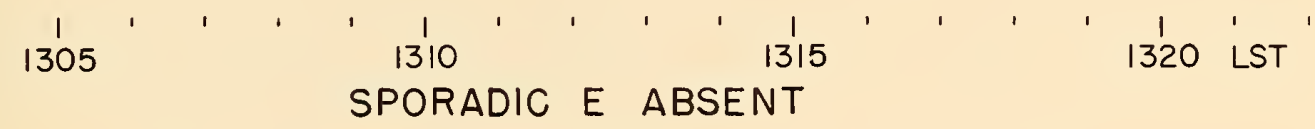

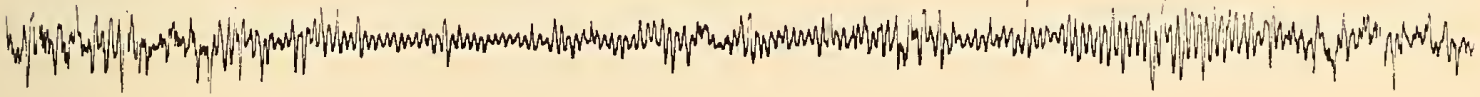

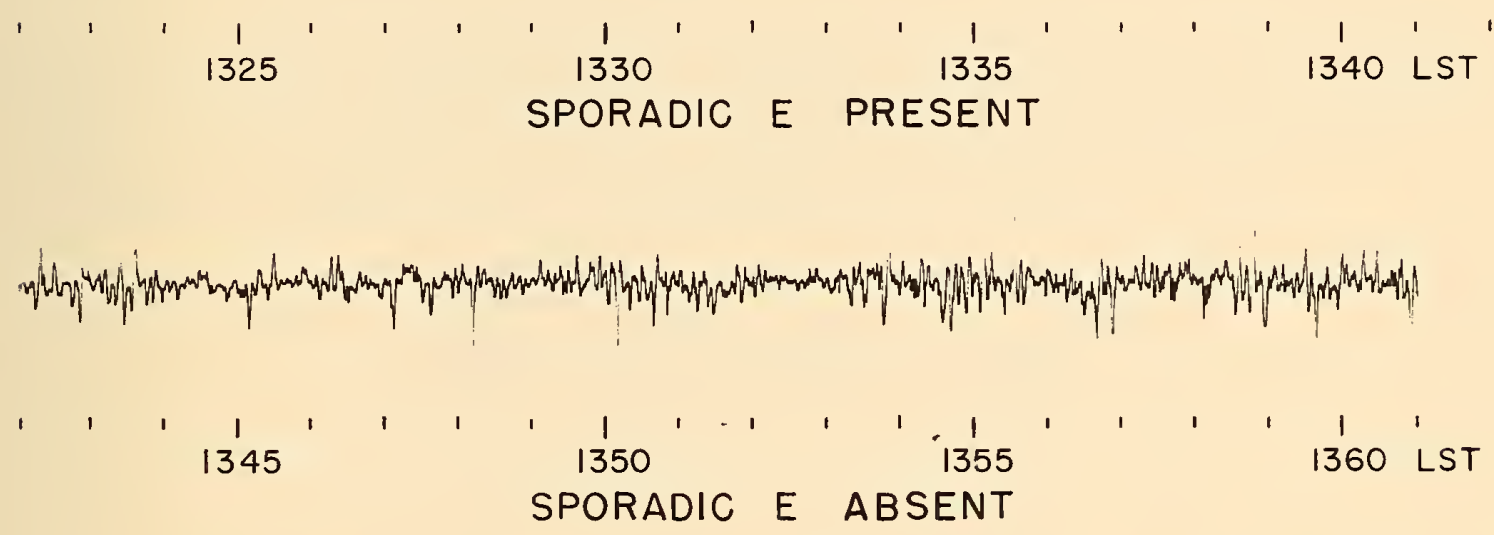

A SCINTILLATION RECORD TAKEN DURING THE PASSAGE OF A SPORADIC-E CLOUD

FIGURE 8 



$$
\begin{aligned}
\mathrm{a} & =\frac{\text { amplitude of the steady component }}{\mathrm{r} \cdot \mathrm{m} \cdot \mathrm{s} \cdot \text { instantaneous amplitude of the random component }} \\
& =\frac{\sqrt{2} \mathrm{r} \cdot \mathrm{m} \cdot \mathrm{s} \text {. instantaneous amplitude of the steady component }}{\mathrm{r} \cdot \mathrm{m} \cdot \mathrm{s} \cdot \text { instantaneous amplitude of the random component }}
\end{aligned}
$$

Norton, ${ }^{11}$ et al., have defined the quantity

$\mathrm{k}^{2}=\frac{2}{a^{2}}=\left[\frac{\mathrm{r} \cdot \mathrm{m} \cdot \mathrm{s} \text {. instantaneous amplitude of the random component }}{\text { r.m.s. instantaneous amplitude of the steady component }}\right]^{2}$

which has the advantage of being a ratio of mean squares. $k$ may be thought of as the r.m.s. noise-to-signal ratio of the radio wave. In the present application "signal" means the steady component unaffected by the irregularities of the ionosphere, and "noise" means the combination of the various diffracted waves.

The Rice distribution degenerates into the familiar Rayleigh distribution in the limit as $\mathrm{k}$ approaches infinity, and approaches a displaced Gauss distribution as $k$ approaches zero. Several values of the parameter $\mathrm{k}$ are indicated on the curve. The details of the derivation of this curve are given in the appendix.

The apparent agreement between the scintillation records and the Rice distribution means that the arbitrary amplitude and power indices may be replaced by the more physically meaningful parameter $\mathrm{k}$. Each depth index naturally covers a considerable range of values of $\mathrm{k}$. Extreme and average values are approximately as shown below.

\begin{tabular}{|c||c|c|c|}
\hline \multirow{2}{*}{$\begin{array}{l}\text { depth } \\
\text { index }\end{array}$} & \multicolumn{3}{|c|}{$\mathrm{k}$} \\
\cline { 2 - 4 } & min. & $\max$. & avg. \\
\hline 1 & .04 & .12 & .05 \\
2 & .05 & .13 & .07 \\
3 & .13 & .35 & .20 \\
4 & .28 & .35 & .31 \\
5 & .47 & $>3$ & 1.41 \\
\hline
\end{tabular}

The family of Rice distributions as defined by Rice ${ }^{9}$ applies to the amplitude of the radio wave and is thus quite convenient for the study of communications signals. For radio-star observations it is usual to employ a square-law detector and thus obtain records which are linear in power. The Rice distributions, $G(P)$, plotted in terms of power, are shown in figure 9. These curves accurately match the distributions of chart deflections which are found experimentally. On these curves the long tail which exists for large values of $k$ is particularly noticeable. The corresponding large deflections of the record are indeed prominent, and may easily give the erroneous impression that they are caused by some special mechanism unrelated to random diffraction. 



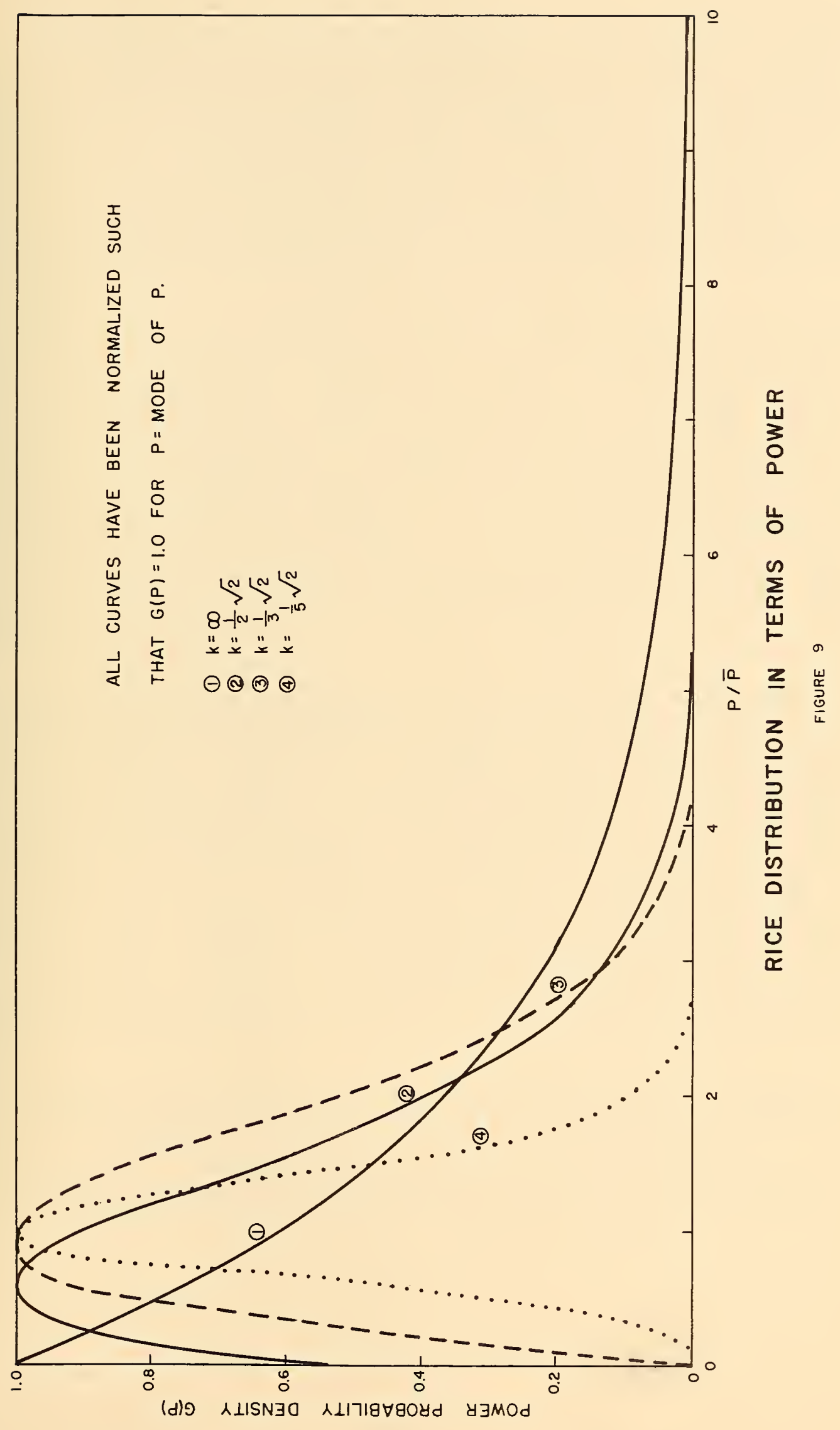



Comparison between the two frequencies. It is generally reported that the scintillation rate is independent of frequency. A casual inspection of the records upholds this belief, but the more detailed analysis made with the computer seems to show that the $108 \mathrm{mc} / \mathrm{s} \mathrm{scint-}$ illations are consistently more rapid than those at $53 \mathrm{mc} / \mathrm{s}$. The reasons for this are not clear; in fact, it would be reasonable to expect just the opposite behavior since the phase index of the diffracting region is presumably greater at the lower frequency. This effect warrants further study, and will be investigated by inspection of the power spectra of the scintillation records.

Booker ${ }^{7}$ has pointed out that the mean square amplitude fluctuation, $\left(\frac{\Delta A}{A}\right)^{2}$, may be expected to vary as $\lambda^{2}$ or as $\lambda^{4}$, depending upon the size of the irregularities compared to a Fresnel zone. Figure 5b shows that, for the few simultaneous records which have been studied, the dependence upon wavelength lies between these two limiting cases with no apparent preference for either. This indicates that significant irregularities must be present with a 0.5 autocorrelation distance of about one kilometer, in good agreement with the scale of irregularities obtained by other methods.

Correlation with spread F. The apparent correlation between amplitude scintillations and spread $F$ is not surprising; similar results have been reported $5,12-17$ by most other workers in the field. In most cases the sounder was not situated in the optimum position for best correlation, and in several of the reports it was only the agreement in diurnal behavior of scintillations and spread $F$ which indicated the possible connection. Briggs 18 has recently made a detailed study of the connection between scintillations and three reasonably well-situated ionospheric sounders. He concludes that spread $F$ occurs in patches having dimensions of about $450 \mathrm{~km}$ northsouth and larger east-west. As Briggs points out, the variation of the correlation coefficient indicates that the scintillations are produced by irregularities at a height of about $300 \mathrm{~km}$, although the figure is admittedly rough.

Our data seem entirely consistent with the results of Briggs. The effective height cannot be read from figure 6 with any accuracy, but it is consistent with 300 or $400 \mathrm{~km}$. The fact that the correlation is already noticeable at 1300 LST, but is not so high as at 1600 , indicates that the patches of spread-F ionization are of the order of $400 \mathrm{~km}$ in extent in a $\mathrm{NE}-\mathrm{SW}$ direction. 

Correlation with sporadic E. A connection of the type seen here between scintillations and sporadic $\mathrm{E}$ has not been reported previously. Most observers have found little or no correlation with sporadic E. Bolton, Slee, and Stanley ${ }^{1}$ found a positive, day-to-day correlation with low-angle scintillations in Australia. This appeared even though the ionosonde was several hundred kilometers from the point of penetration of the $\mathrm{E}$ region by the line of sight to the radio star. Wild and Roberts 15 found that this effect occurred only for daytime (or summer) scintillations. (Using a single radio star, it was impossible to distinguish between diurnal and seasonal variations.) Because of the patchy nature of sporadic $\mathrm{E}$ and the hundreds of kilometers between the ionosondes and their optimum position, Wild and Roberts were forced to consider only those days which showed significantly large or small, values of $\mathrm{fEs}$ in agreement at two wellseparated locations. Hartz ${ }^{14}$ noted that the diurnal variations of scintillations and sporadic $\mathrm{E}$ in Canada are opposite but he found neither positive nor negative correlation on a daily or hourly basis. In this country, Dueno 19 found some correlation between sporadic $\mathrm{E}$ and low-angle scintillations in the winter.

For E-region effects, the present experiment is potentidlly more sensitive than any of those just mentioned because the Ellsworth ionosonde is located in precisely the optimum position, but the limited sample of data (six months) now available cannot disclose diurnal or seasonal effects, and is short enough to demand a careful evaluation of the significance of whatever correlations do appear. Some of the correlation coefficients shown in figures 6 and 7 differ from zero by two or three times the computed standard deviation. This fact alone would not be sufficient to inspire much confidence in them, but it seems most significant that the peaks (or dips) in the correlation appear at the proper times, and therefore at the proper effective heights, for the various layers. This concerted behavior of the correlation coefficients lends much more confidence to the entire picture than any significance test on the individual coefficlents could do.

At flrst glance it seems paradoxical that scintillations, an effect of irregularities in the ionosphere, should be negatively correlated with sporadic $\mathrm{E}$. Actually, it is quite in accord with the behavior of sporadic $\mathrm{E}$ that at least some types may be indicative of unusually calm or quiet conditions in the ionosphere. For example, it is common knowledge that the fading rate of a signal propagated by ionospheric scatter drops markedly when sporadic E appears. It may be that the normal $\mathrm{E}$ region is in a state of turbulence and contributes a small part to the total scintillation of radio stars, and that sporadic $\mathrm{E}$ appears at times when the region is unusually quiet, allowing the formation of thin layers with sharp ionization gradients, and the scintillations are correspondingly reduced. Reflection from the sharp gradients might also explain a decrease in average flux. 



\section{Acknowledgment}

This experiment could not have been performed without the cooperation of several people. Among them are E. R. Schiffmacher and H. A. Erickson who have been responsible for the maintenance and operation of the scintillation receivers, $R$. F. Carle who has established and operated the ionosonde at Ellsworth, and R. C. Lamb and Mrs. C. I. Enfield who have assisted with the analysis of the data. 


$$
\text { - }
$$


1. Lawrence, R. S.; "An investigation of the perturbations imposed upon radio waves penetrating the ionosphere," Proc. I.R.E., vol. 46, pp. 315-320; (1958).

2. Cramér, H.; "Mathematical methods of statistics," Princeton U. Press; p. 359; (1954).

3. Hewish, A.; "The diffraction of galactic radio waves as a method of investigating the irregular structure of the ionosphere," Proc. Roy. Soc. A, London, vol. 214, pp. 494-514; (1952).

4. Little, C. G., et al.; "Radio properties of the auroral ionosphere. quarterly progress reports Nos. 1-5, 7, 8," Geophys. Inst., U. of Alaska; (1958).

5. Iittle, C. G., and Maxwe1l, A.; "Fluctuations in the intensity of radio waves from galactic sources," Phil. Mag., ser. 7, vol. 42, pp. 267-278; (1951).

6. Iittle, C. G.; "The origin of the fluctuations in galactic noise," Ph. D. thesis, Manchester U., England; (1952).

7. Booker, H. G.; "The use of radio stars to study irregular refraction of radio waves in the ionosphere," Proc. I.R.E., vol. 46, pp. 298-314; (1958).

8. Thomas, J. A.; "Sporadic E at Brisbane," Austr. J. Phys., vol. 9, pp. 228-246; (1956).

9. Rice, S. 0.; "Mathematical analysis of random noise," Bell System Tech. J., vols. 23 \& 24, pp. 282-332 and 46-156; (1944 and 1945).

10. Ratcliffe, J. A.; "Some aspects of diffraction theory and their application to the ionosphere," Rep. Prog. Phys., vol. 19, pp. 188-267; (1956).

11. Norton, K. A., et al.; "The probability distribution of the amplitude of a constant vector plus a Rayleigh-distributed vector" Proc. I.R.E., vol. 43 pp. 1354-1361; (1955).

12. Ryle, M. and Hewish, A.; "The effects of the ionosphere on radio waves from discrete sources in the galaxy," Mon. Not. Roy. Astron. Soc., vol. 110 pp. 381-394; (1950). 

13. Bolton, J. G.; Slee, O. B.; and Stanley, G. J.; "Galactic radiation at radio frequencies VI; low-altitude scintillations of the discrete sources," Austr. J. Phys., vol. 6, pp. 434-451; (1953).

14. Hartz, T. R.; "Radio star scintillations and the ionosphere," Can. J. Phys., vol. 33, pp. 476-482; (1955).

15. Wild, J. P. and Roberts, J.A.; "Regions of the ionosphere responsible for radio star scintillations," Nature, vol. 178, pp. 377-378; (1956).

16. Dagg, M.; "Diurnal varlations of radio-star scintillations, spread F, and geomagnetic activity," J. Atm. Terr. Phys., vol. 10, pp. 204-214; (1957).

17. Koster, J. R.; "Radio star scintillations at an equatorial station," J. Atm. Terr. Phys., vol. 12, pp. 100-109; (1958).

18. Briggs, B. H.; "A study of the ionospheric irregularities which cause spread-F echoes and scintillations of radio stars," J. Atm. Terr. Phys., vol. 12, pp. 34-45; (1958).

19. Dueño, B.; "Study and interpretation of low angle fluctuations from the radio star Cassiopeia as observed at Ithaca, N.Y.," Tech. Rept. No. 27, Cornell U. School of Elec. Eng., Ithaca, N.Y.; (1955).

20. Hoe1, P. G.; "Introduction to mathematical statistics," p. 213; John Wiley \& Sons. (1956). 

The relation between amplitude and power indices

for a Rice distribution.

Rice $^{9}$ has shown that the probability distribution function (pdf) of the resultant instantaneous amplitude (A) of the sum of a unit reference vector which represents a sinusoidal voltage of constant amplitude and phase, and a Rayleigh distributed vector which represents a random component with r.m.s. voltage $\mathrm{k}(=\sqrt{2} / \mathrm{a}$, in Rice's notation) is given by

$$
f(A)=\frac{2 A}{k^{2}} \exp \left(-\frac{A^{2}+1}{k^{2}}\right) I_{0}\left(\frac{2 A}{k^{2}}\right)
$$

where $I_{0}$ is the modified Bessel function of the first kind. It is possible to compute from ( 1 ) the quantities

$$
\begin{aligned}
& \left(\frac{\Delta A}{A}\right)^{2} \equiv \frac{1}{N} \sum_{i=1}^{N}\left(\frac{A_{i}-\bar{A}}{\bar{A}}\right)^{2} \text { and } \\
& \frac{\Delta P}{P} \equiv \frac{1}{\bar{N}} \sum_{i=1}^{N} \frac{\left|P_{i}-\bar{P}\right|}{\bar{P}}
\end{aligned}
$$

where $A^{2}=P$; and $\bar{A}$ and $\bar{P}$ are the means of $A$ and $P$ respectively. Before proceeding to this, it will be helpful to make some preliminary computations.

$$
\left(\frac{\Delta A}{A}\right)^{2}=\frac{\overline{A^{2}}-\bar{A}^{2}}{\bar{A}^{2}}=\frac{\overline{A^{2}}}{\bar{A}^{2}}-1
$$

To evaluate $\frac{\Delta P}{P}$ we recall from statistics that the expected value $E[g(x)]$ of the quantity $g(x)$ is given by

$$
E[g(x)]=\int_{-\infty}^{\infty} f(x) g(x) d x \text { where } f(x) \text { is the pdf of } x \text {. }
$$



Thus,

$$
\begin{aligned}
E\left(\frac{|\mathrm{P}-\overline{\mathrm{P}}|}{\overline{\mathrm{P}}}\right) & \equiv \frac{\Delta \mathrm{P}}{\mathrm{P}}=\frac{1}{\overline{\mathrm{P}}} \int_{0}^{\infty}|\mathrm{P}-\overline{\mathrm{P}}| \mathrm{f}(\mathrm{P}) \mathrm{dP} \\
& =\frac{1}{\overline{\mathrm{P}}}\left[\int_{\overline{\mathrm{P}}}^{\infty}(\mathrm{P}-\overline{\mathrm{P}}) \mathrm{f}(\mathrm{P}) \mathrm{dP}-\int_{0}^{\overline{\mathrm{P}}}(\mathrm{P}-\overline{\mathrm{P}}) \mathrm{f}(\mathrm{P}) \mathrm{dP}\right] \\
& =\frac{1}{\overline{\mathrm{P}}}\left[\int_{0}^{\infty}(\mathrm{P}-\overline{\mathrm{P}}) \mathrm{f}(\mathrm{P}) \mathrm{dP}-2 \int_{0}^{\overline{\mathrm{P}}}(\mathrm{P}-\overline{\mathrm{P}}) \mathrm{f}(\mathrm{P}) \mathrm{dP}\right] \\
& =\frac{1}{\overline{\mathrm{P}}}\left[2 \overline{\mathrm{P}} \mathrm{F}_{0}(\mathrm{P})-2 \overline{\mathrm{P}}_{\bar{S}}\right]
\end{aligned}
$$

where

$$
F_{0}(P)=\int_{0}^{\bar{P}} f(P) d P \text { and } \bar{P}_{S}=\int_{0}^{\bar{P}} P f(P) d P .
$$

We are interested in obtaining the pdf of the power "P" from (1). The following theorem 19 will allow us to make this transformation. "If $x=h(y)$ is an increasing or decreasing function of $y$ and if $f(x)$ is the pdf of $x$, then $g(y)$ is the pdf of $y$ where

$$
g(y)=f[h(y)]\left|h^{\prime}(y)\right| \cdot "
$$

Thus for the transformation

$$
\begin{aligned}
A^{2} & =P, \\
h(P) & =P^{\frac{1}{2}} ; \\
h^{\prime}(P) & =\frac{1}{2} P^{-\frac{1}{2}} ; \\
g(P) & =\frac{f\left(P^{\frac{1}{2}}\right)}{2 / P^{\frac{1}{2}}} ; \text { or in terms of } A, \\
g(P) & =g\left(A^{2}\right)=\frac{f(A)}{2 A} .
\end{aligned}
$$

We may now proceed to the computation of $\left(\frac{\Delta A}{A}\right)^{2}$ and $\frac{\Delta P}{P}$.

$$
\bar{A}=\int_{0}^{\infty} A f(A) d A=\frac{2}{k^{2}} \int_{0}^{\infty} A^{2} \exp \left[-\frac{A^{2}+1}{k^{2}}\right] I_{0}\left(\frac{2 A}{k^{2}}\right) d A
$$





$$
\begin{aligned}
=\frac{\mathrm{k} \sqrt{\pi}}{2} & e^{-1 / 2 k^{2}}\left[\left(1+\frac{1}{k^{2}}\right) I_{0}\left(\frac{1}{2 k^{2}}\right)+\frac{1}{k^{2}} I_{1}\left(\frac{1}{2 k^{2}}\right)\right] \\
\bar{P} & =\overline{A^{2}}=\int_{0}^{\infty} \operatorname{Pg}(P) d P \\
& =\frac{2}{k^{2}} \int_{0}^{\infty} A^{3} \exp \left(-\frac{A^{2}+1}{k^{2}}\right) I_{0}\left(\frac{2 A}{k^{2}}\right) d A \\
& =1+k^{2}
\end{aligned}
$$

Then from (4), (7) and (8)

$$
\left(\frac{\Delta A}{A}\right)^{2}=\frac{4\left(1+k^{2}\right) \exp \left(\frac{1}{k^{2}}\right)}{k^{2} \pi\left[\left(1+\frac{1}{k^{2}}\right) I_{0}\left(\frac{1}{2 k^{2}}\right)+\frac{1}{k^{2}} I_{1}\left(\frac{1}{2 k^{2}}\right)\right]^{2}}-1
$$

As $k \rightarrow \infty$

$$
\left(\frac{\Delta A}{A}\right)^{2} \rightarrow \frac{4}{\pi}-1
$$

For $\frac{\Delta \mathrm{P}}{\mathrm{P}}$ we must evaluate

$$
\bar{P}_{s}=\frac{2}{k^{2}} \int_{0}^{\sqrt{\bar{P}}} A^{3} \exp \left(-\frac{A^{2}+1}{k^{2}}\right) I_{0}\left(\frac{2 A}{k^{2}}\right) d A
$$

(11) cannot be integrated in closed form; however, Rice has shown that when $\mathrm{k}<\frac{\sqrt{2}}{3}$

$$
f(A) \approx \frac{1}{k \sqrt{\pi}} \exp -\left(\frac{A-\bar{A}}{k}\right)^{2},
$$



the Gaussian pdf, for which

$$
\bar{A}^{2}=\overline{A^{2}}-\frac{k^{2}}{2} \text {. }
$$

Thius when $k<\frac{\sqrt{2}}{3}$, from (8)

$$
\bar{A}^{2}=1+\frac{k^{2}}{2}
$$

Then from (4)

$$
\begin{gathered}
\left(\frac{\Delta A}{A}\right)^{2}=\frac{2\left(k^{2}+1\right)}{k^{2}+2}-1 . \\
\bar{P}_{S}=\frac{1}{k \sqrt{\pi}} \int_{0}^{\sqrt{\bar{P}}} A^{2} \exp -\left(\frac{A-\bar{A}}{k}\right)^{2} \text { dA Let } t=\frac{(A-\bar{A})}{k} .
\end{gathered}
$$

Then $\overline{\mathrm{P}}_{\mathrm{S}}=\frac{1}{\sqrt{\pi}} \int_{-t_{1}}^{t_{2}}(k t+\bar{A})^{2} \exp \left(-t^{2}\right) d t$

where $t_{2}=\left(\frac{1}{k^{2}}+1\right)^{\frac{1}{2}}-\left(\frac{1}{k^{2}}+\frac{1}{2}\right)^{\frac{1}{2}}$ and $t_{1}=\left(\frac{1}{k^{2}}+\frac{1}{2}\right)^{\frac{1}{2}}$.

For $k<\frac{\sqrt{2}}{3}, \int_{-t_{1}}^{0}(k t+\bar{A})^{2} \exp \left(-t^{2}\right) d t \approx \int_{-\infty}^{0}(k t+\bar{A})^{2} \exp \left(-t^{2}\right) d t$

Thus $\bar{P}_{s}=\frac{1}{\sqrt{\pi}}\left[\int_{0}^{t} 2(k t+\bar{A})^{2} \exp \left(-t^{2}\right) d t\right.$

$$
\left.+\int_{-\infty}^{0}(k t+\bar{A})^{2} \exp \left(-t^{2}\right) d t\right]
$$





$$
\begin{aligned}
& =\frac{1}{\sqrt{\pi}}\left[\frac{k^{2}}{2}\left(\frac{\sqrt{\pi}}{2}-t_{2} \exp \left(-t_{2}^{2}\right)\right)+k\left(1+\frac{k^{2}}{2}\right)^{\frac{1}{2}}\left(2-\exp \left(-t_{2}^{2}\right)\right)\right. \\
& \left.+\frac{\sqrt{\pi}}{2}\left(1+\frac{k^{2}}{2}\right)+\left(1+k^{2}\right) \int_{0}^{t} 2 \exp \left(-t^{2}\right) d t\right]
\end{aligned}
$$

and finally,

$$
\begin{aligned}
F_{0}(P) & =\frac{1}{k \sqrt{\pi}} \int_{0}^{\sqrt{\bar{P}}} \exp -\left(\frac{A-\bar{A}}{\mathrm{k}}\right)^{2} d A=\frac{1}{\sqrt{\pi}} \int_{-t_{1}}^{t_{2}} \exp \left(-t^{2}\right) d t \\
& \Leftrightarrow \frac{1}{\sqrt{\pi}} \int_{0}^{t_{2}} \exp \left(-t^{2}\right) d t+\frac{1}{2}
\end{aligned}
$$

From (5), (8), (14) and (15) we may compute $\frac{\Delta P}{P}$ for $k<\frac{\sqrt{2}}{3}$. In the general development $\left(\frac{\Delta A}{A}\right)^{2}$ was found in the limit as $k \rightarrow \infty$. This is the case where the unit vector becomes negligible compared to the Rayleigh distributed vector. Then ( 1 ) becomes

$$
f(A)=2 \frac{A}{k^{2}} \exp \left(-\frac{A^{2}}{k^{2}}\right)
$$

simply the Rayleigh pdf. To complete the evaluation of $\lim _{k \rightarrow \infty} \frac{\Delta P}{P}$

we find $\bar{P}_{S}=\frac{1}{k^{2}} \int_{0}^{\bar{P}} P \exp \left(-\frac{P}{k^{2}}\right) d P=k^{2}\left(1-\frac{2}{e}\right)$ 

and $F_{0}(P)=\frac{1}{k^{2}} \int_{0}^{\bar{P}} \exp \left(-\frac{P}{k^{2}}\right) d P=I-\frac{1}{e}$

Thus from (5), (16) and (17), $\lim _{k \rightarrow \infty} \frac{\Delta P}{P}=\frac{2}{e}$.

The table below gives values of $\frac{\Delta P}{P}$ and $\left(\frac{\Delta A}{A}\right)^{2}$ for the Rayleigh limit $(k \rightarrow \infty)$ and for the Gaussian region $\left(k<\frac{\sqrt{2}}{3}\right)$.

\begin{tabular}{|c|c|c|}
\hline$k$ & $\frac{\Delta P}{P}$ & $\left(\frac{\Delta A}{A}\right)^{2}$ \\
\hline 0 & 0 & 0 \\
\hline$\frac{\sqrt{2}}{10}$ & .153 & .010 \\
\hline$\frac{\sqrt{2}}{5}$ & .295 & .038 \\
\hline$\frac{\sqrt{2}}{4}$ & .359 & .059 \\
\hline$\infty$ & $\frac{2}{e}=.735$ & .274 \\
\hline
\end{tabular}

From these points, the curve shown in figure 4 has been drawn, using the fact that there should be a smooth transition from the Rayleigh point to the Gaussian region. The points for $\mathrm{k}=\sqrt{2}, \frac{\sqrt{2}}{2}$, and $\frac{\sqrt{2}}{3}$ have been placed on this curve at the proper value of $\left(\frac{\Delta A}{A}\right)^{2}$ as computed from (10) 

NBS

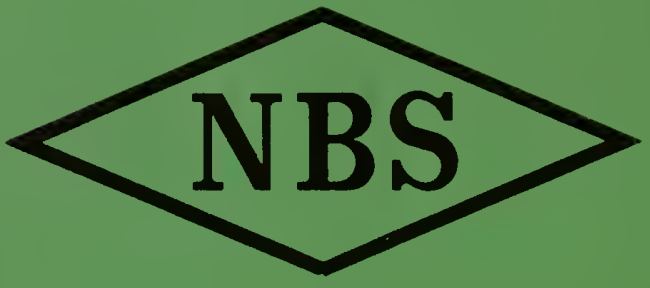

NBS r 




